\title{
Oral mucositis: the hidden side of cancer therapy
}

\author{
Claudio Pulito ${ }^{1}$, Antonio Cristaudo², Caterina La Porta ${ }^{3,4}$, Stefano Zapperi, ${ }^{5,6}$, Giovanni Blandino ${ }^{1}$, \\ Aldo Morrone ${ }^{7}$ and Sabrina Strano ${ }^{8^{*}}$
}

\begin{abstract}
Inflammation response of epithelial mucosa to chemo- radiotherapy cytotoxic effects leads to mucositis, a painful side effect of antineoplastic treatments. About $40 \%$ of the patients treated with chemotherapy develop mucositis; this percentage rises to about $90 \%$ for head and neck cancer patients (HNC) treated with both chemo- and radiotherapy. 19\% of the latter will be hospitalized and will experience a delay in antineoplastic treatment for highgrade mucositis management, resulting in a reduction of the quality of life, a worse prognosis and an increase in patient management costs. Currently, several interventions and prevention guidelines are available, but their effectiveness is uncertain. This review comprehensively describes mucositis, debating the impact of standard chemo-radiotherapy and targeted therapy on mucositis development and pointing out the limits and the benefits of current mucositis treatment strategies and assessment guidelines. Moreover, the review critically examines the feasibility of the existing biomarkers to predict patient risk of developing oral mucositis and their role in early diagnosis. Despite the expression levels of some proteins involved in the inflammation response, such as TNF-a or IL-1 $\beta$, partially correlate with mucositis process, their presence does not exclude others mucositis-independent inflammation events. This strongly suggests the need to discover biomarkers that specifically feature mucositis process development. Non-coding RNAs might hold this potential.
\end{abstract}

Keywords: Oral mucositis, HNC, Biomarker, Cytokine, Non-coding RNA, Quality of life

\section{Background}

The advent of chemotherapy (CT) in 1940 led to a dramatic increase in mucositis adverse events, generically identified as stomatitis. The lack of efficacious therapies and of prevention guidelines for stomatitis consistently decreased patient quality of life and prognosis. Only sixty years later the complex mechanisms underlying mucositis pathogenesis were discovered and in 2007 the term mucositis was adopted to describe lesions associated to chemo- and/or radiotherapy (RT) cytotoxic effects.

\footnotetext{
* Correspondence: sabrina.strano@ifo.gov.it

${ }^{8}$ SAFU Laboratory, Department of Research, Advanced Diagnostic, and

Technological Innovation, IRCCS, Regina Elena National Cancer Institute, Via Elio Chianesi, 53, 00144 Rome, Italy

Full list of author information is available at the end of the article
}

Mucositis affects all gastro-intestinal tract and oral cavity inducing patient pain, inability to eat, weight loss and local infection. Furthermore, patients affected by a high-grade mucositis have to reduce chemotherapy regimen with delayed cancer treatment and worse prognosis. About $30-40 \%$ of cancer patients treated with chemotherapy develops mucositis, this percentage rises to $60-85 \%$ for patients undergoing to an hematopoietic stem cell transplantation (HSCT) and to almost 90\% for head and neck cancer (HNC) patients treated with radio- plus chemotherapy [1]. Mucositis development leans not only on anticancer regimen, doses and number of cycles, but, also, on patients characteristics. Female patients, indeed, have a greater risk of developing severe mucositis when treated with 5-Fluoruracil (5-FU) [2], likewise to patients with a deficiency in the dihydropyrimidine dehydrogenase, 
a critical enzyme for 5-FU catabolism [3]. Conversely, patients affected by an aberrant epithelial proliferation, as psoriasis, exhibit a reduction in mucositis incidence [1]. In general old age, female gender, high bodyweight, a reduced clearance of drugs and genetic susceptibility are mucositis-related development risk factors.

Mucositis epidemiological data are still underestimated and contradictory. This adverse event, indeed, is often recorded only when patients develop a high-grade mucositis for which a clinical treatment is required. Moreover, there is not a standard scale to score its severity, thus making the disease staging and assessment rather difficult to compare. Currently, there are different scales to grade mucositis, whose parameters vary among them. The World Health Organization (WHO) scale for oral mucositis (OM) evaluation accounts for objective criteria, such as the presence of either erythema or ulceration. These are functional criteria based on the ability of the patient to eat. A quantitative scale that assesses ulceration dimension is used by the Oral Mucositis Assessment Scales (OMAS). The Eastern Cooperative Oncology Group (ECOG) mucositis scale is reported in the common toxicity criteria guide in which mucositis severity is differently classified based on the anatomic site of development. Similarly, the National Cancer Institute (NCI) provides in the Common Terminology Criteria for Adverse Event (CTCAE) mucositis severity measure scale based on anatomic site of development and on the kind of treatment, either chemo or radiotherapy [4].

\section{Mucositis pathogenesis}

Mucositis development consists of a cascade of events that can be divided in five stages occurring consecutively and mechanistically linked (Fig. 1). The injury of mucosa membranes, named mucositis initiation phase, is caused by either radio- and/or chemotherapy. This stage occurs concurrently with chemo- or radiotherapy administration. Systemic chemotherapy and radiotherapy induce tissue damage causing reactive oxygen species (ROS) release, DNA damage thereby leading to cell death of the basal and suprabasal epithelial cells [5]. In particular, DNA strands breaks lead to the activation of the apoptotic process which is regulated by $\mathrm{p} 53$ activation and increased caspase 3 [6]. As a direct consequence of it, dead cells release endogenous damage-associated pattern molecules (DAMPs). This primary damage response characterizes the second stage of mucositis development (Fig. 1). During this stage cells of the injured mucosa promote the transcription of several genes involved in the mucositis process. In this molecular scenario, the nuclear factor- $\mathrm{kB}(\mathrm{NF}-\mathrm{kB})$ represents the main transcriptional mediator modulating over 200 genes associated with proinflammatory cytokines (tumor necrosis factor $\alpha /$ TNF- $\alpha$; interleukin-6/IL-6; interleukin-1 $\beta / \mathrm{IL}-1 \beta$ ), cell adhesion molecules, stress responders and cytokine modulators $[7$, 8]. The presence of pro-inflammatory cytokines is, also, reported within the mucosa, where they seem to induce early damage of connective tissue and endothelium, as well as to inhibit tissue oxygenations and to favor epithelial basal cell
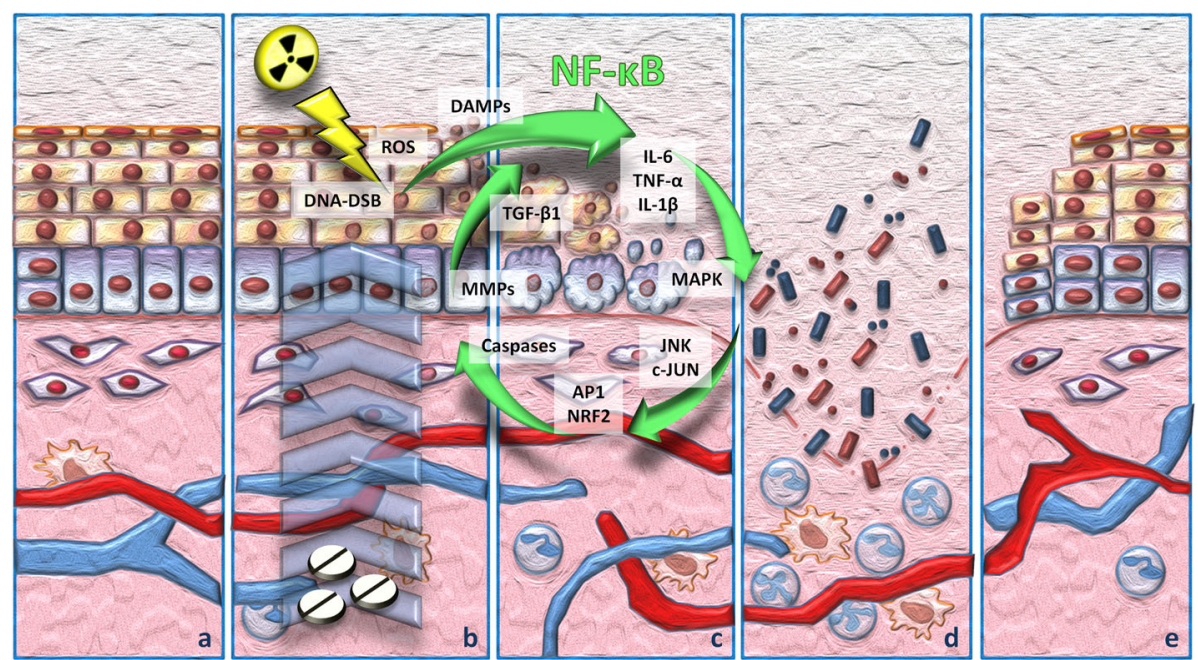

Fig. 1 Mucositis pathobiology: (a) normal tissue; (b) initiation phase and primary injury response. Radio and chemotherapy-induced damages lead to an increase in DNA double strand brakes and ROS production with a consequent induction of cell apoptosis and DAMPS release. DAMPs and ROS signaling promote the NF-KB-mediated transcription of cytokines; (c) amplification of the injury signal. The effectors produced during the previous phase lead to an amplification of the injury signal. The released TNF-a initiates the activation of MAPK that sustains NF-KB activity. During this stage, the primary damage signaling is amplified through positive-feedback loop mechanisms. (d) ulceration. Breaks in the submucosa allows to microorganisms to invade this tissue district leading to mononuclear-infiltrating cells-mediated inflammation response; (e) tissue reepithelialization. Stimuli from the submucosa extracellular matrix and mesenchyme promote the healing process 
death [5]. During this phase the activation of the immediate response genes, as well as the activation of c-JUN and the c-JUN aminoterminal kinase (JNK) takes place; thereby following the release of cell membrane bound molecules lead to activation of other transcription factors involved in the process [9]. Among them, the nuclear factor erythroid 2-related factor 2 (NRF2) is a basic leucin zipper protein that promotes the expression of antioxidant proteins as consequence of injury and inflammation process [10]. Moreover, anticancer treatment damages also fibroblasts, thus leading to the activation of protein-1 (AP1) and the consequent secretion of metalloproteinases (MMPs), such as MMP1 and MMP3 which degrade collagenous subepithelia matrix and disaggregate the epithelial basement membrane respectively $[5,11]$.

The effectors produced during the primary damage response lead to an amplification of the injury signal (Fig. 1). Concurrently with the activation of other pathways the primary damage is amplified through positivefeedback loop mechanisms. The released TNF- $\alpha$, indeed, initiates the activation of the mitogen activated protein kinase (MAPK) on target cells and, in the same time, sustains NF-kB activity. During this stage, several damages impair the mucosa and sub mucosa structures. However, patients exhibit few symptoms and the mucosa does not reveal any macroscopic evidence of injury. MAPK signaling mediates caspase 3 activation and cell death through the activation of JNK that in turn, finely tunes AP1 transcriptional activity [9]. Moreover, the high levels of TNF- $\alpha$ activate sphingomyelinase increasing the pro-apoptotic signal mediated by the ceramide pathway and, together with IL-1 $\beta$, modulate MMP1 and MMP3 activities [11, 12]. Besides, the injured keratinocytes release the transforming growth factor beta 1 (TGF- $\beta 1$ ), that in turn, inhibits cell cycle, recruits leucocytes and sustains NF- $\mathrm{kB}$ activity, thus improving the damage-mediated signaling [13].

Clinical manifestations of mucositis are appreciable at the fourth stage of the inflammation process, the ulceration phase. During this stage, mucosa and sub mucosal integrity is compromised, patients complain of pain and may need caregivers management (Fig. 1). The presence of breaks in the submucosa, allows several microorganisms, symbiotic inhabitant of the healthy mucosa, to invade this tissue district leading to mononuclerinfiltrating cells-mediated inflammation response, thus promoting new pro-inflammatory cytokines release that amplify expression of pro-apoptotic mediators and increase tissue damage [14, 15]. Patients, based on the duration and the extent of neutropenia, can develop bacteremia or septicemia, mainly caused, in OM, by streptococci and staphylococci [16]. Mucositis is an acute event that mostly self-resolves as the anticancer treatment ends. At this stage the healing process is activated, during which stimuli from the submucosa extracellular matrix and mesenchyme promote tissue reepithelialization [5, 17].

\section{Role of "old" and "new" anticancer agents in mucositis development}

Mucositis incidence and its severity depend on chemotherapy regimen, doses and treatment timing. Antimetabolites, platin-derived, taxanes, anthracyclines, irinotecan and alkylating agents can promote mucositis, whose severity and development site vary among the different drugs. Indeed, the antimetabolites drugs, S-1 and capecitabine are associated to a lower risk of mucositis development compared to the 5-FU treatment [18]. Conversely, when capecitabine is associated to irinotecan (XELIRI regimen), a topoisomerase 1 inhibitor, it induces higher gastrointestinal mucositis (GIM) events compared to fluoruracil plus irinotecan combination (FOLFIRI) [19]. Nevertheless, patients treated with FOLFIRI regimen have a high probability to develop mucositis compared to patients treated with irinotecan plus oxaliplatin (FOLFOX) [19]. The role of irinotecan treatment in GIM development has been extensively studied so far. Irinotecan-mediated GIM clinical manifestation is characterized by two phases. Initially, treatment promotes the cholinergic syndrome and an early-onset diarrhea caused by an excess acetylcholine secretion due to the inhibition of acetyl cholinesterase. Afterwards, patients develop a late-onset diarrhea as a consequence of the irinotecan treatment that leads to mucin hyper-secretion, a reduction in goblet cell numbers and a general disaggregation of the gastrointestinal mucosa structure [20].

Cisplatin has been reported to induce OM through an indirect inhibition of mucin secretion, while it specifically damages the ileal mucosa rather than the remaining gastro intestinal tract [21]. GIM severity is higher in patients treated with cisplatin than in patients treated with other platinum-derived drugs, such as oxaliplatin and carboplatin [22].

Antineoplastic agents such as taxanes promote mucositis in a wide range of patients. However, only few of them develop a high grade mucositis; they generally present a mild or moderate event. Notably, docetaxel treatment is associated with a higher risk of mucositis development compared to paclitaxel [23].

The risk to develop mucositis rises when chemotherapy is associated to radiotherapy. Almost the $90 \%$ of HNC patients, indeed, develop mucositis when treated with chemo plus radiotherapy. Notably, HNC patients treated with cisplatin plus RT specifically develop oral mucositis [24]. In addition, patients receiving conventional RT fractions show a higher mucositis development risk compared to patients treated with high-dose 
single-fraction IMRT (5.1 versus 4.1-fold increased risk) [25]. During RT regimen, high-grade mucositis is more probably detectable either in patients characterized by a HPV/p16-negative status [26] or in those producing an elevated salivary cytokine, IL- 6 and IL- $1 \beta$, concentration [27]. Although the biological sequence of mucositis process is similar, radiotherapy treatment exerts its action on the target tissue within few seconds of exposure compared to CT. Irradiated patients complain GI burning pain just after the first week of treatment, while develop ulceration between the second and the third week of therapy. Unfortunately, RT-associated lesions persist for over six weeks after the latest session [28], affecting significantly the quality of life of the patients.

Beside standard chemo- and radiotherapy an increasing number of targeted agents is currently used in clinical practice for the management of different types of cancer. The target-specificity allows these new agents to have high efficacy and, at the same time, to promote less toxicity than standard CT. Nevertheless, clinicians face off with new toxicities whose characteristics vary accordingly to the administered target drugs. Among them, the mammalian target of rapamycin (mTOR)-inhibitor promotes a severe mucosal toxicity that differs from conventional oral mucositis. The mTOR-inhibitor-associated stomatitis (mIAS) is, indeed, smaller, relative shallow and extremely painful. Macroscopically, it presents a central necrotic area and a surrounding erythematous halo [29-31] (Fig. 2). It usually develops within five days after the first cycle of treatment and either improves or resolves spontaneously even during mTOR inhibitor regimen therapy [32]; however, it is often cause of a re-modulation of therapy dosage or, in presence of a high grade mIAS of treatment discontinuation. In the BOLERO-2 trial, indeed, the combination treatment of everolimus, an mTOR inhibitor, with examestane was limited by a high incidence of all-grade stomatitis in metastatic breast cancer women (67\% of all-grade stomatitis, $33 \%$ grade 2 and $8 \%$ grade 3) [33]. Notably, patients treated with mTOR-inhibitors, such as everolimus, tenserolimus or ridaforolimus, exhibit an increased risk to develop oral stomatitis and enteritis [34]. mIAStoxicity incidence changes accordingly to cancer types. Renal cell carcinoma (RCC) patients, in effect, present a lower risk to develop mIAS than astrocytoma, gastric and breast cancer patients [33]. This is also due to the characteristics of the drug that is associated to the mTOR-inhibitor that vary among the different cancer types, based on the clinical guidelines.

The epidermal growth factor (EGFR) inhibitorsassociated mucosal lesions occur in $15 \%$ of treated patients [35]. Clinically they appear as limited lesions characterized by a moderate erythema, sometimes non dissimilar to an aphthous like lesions [36] (Fig. 2). As for mIAS, the onset is concomitant with the first cycle of treatment, may potentially affect all the non-keratinized area and can resolve autonomously during treatment [36]. Less than $1 \%$ of patients treated in mono-therapy
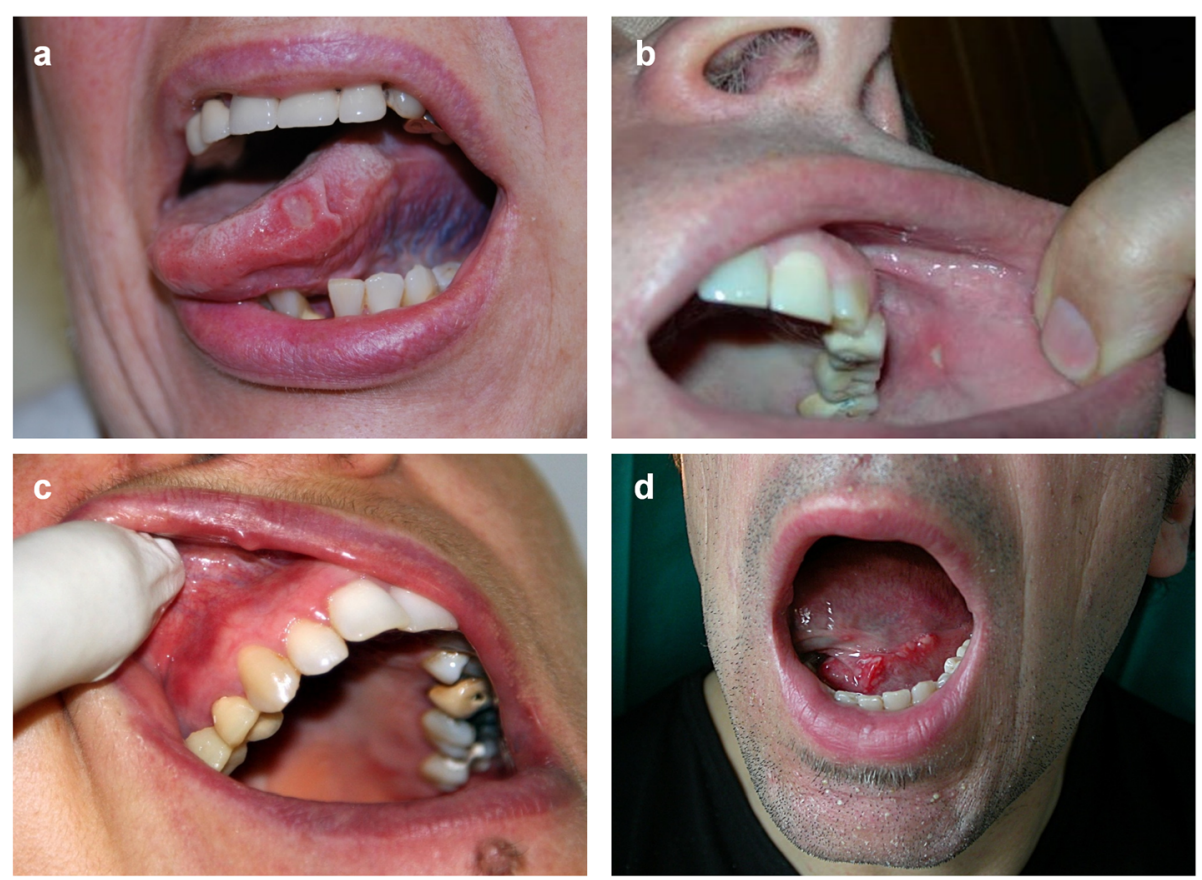

Fig. 2 Representative images of mucositis induced by target therapies. (a-b) patchy ulcerations (aphtous ulcerations) induced by cetuximab, (c) erythema of the mucosa induced by temsirolimus and (d) ulcerations bleeding with minor trauma induced by everolimus 
with anti-EGFR antibodies, cetuximab or panitunumab, or EGFR-tyrosine kinase inhibitor (TKi), erlotinib or gefinitib, develop a high grade mucosal lesion, that in a very few cases require a treatment ri-modulation or suspension [37-39]. Conversely, the incidence and the severity of the lesion increase in those patients treated with a multi targeted $\mathrm{TKi}$, such as afatinib, lapatinib or dacomitinib [40-42]. Indeed these cancer treatments are, associated with a higher incidence of all-grade mucositis compared to other EGFR-TKi ( $40 \%$ vs. $15 \%$ of all-grade, 8.7 vs. $1 \%$ of grade $\geq 3$ ) [43] or to anti-EGFR monoclonal antibodies therapy [32]. Although monotherapy with anti EGFR antibodies or TKi causes few mucosal lesions, these drugs are often associated to cytotoxic agents that cause an increase in mucositis incidence and severity. Indeed, the relative risk to develop high-grade mucosal lesions $(\geq 3)$ significantly rises when cetuximab or panitunumab are administrated concomitantly with cisplatin, 5-FU, FOLFIRI or FOLFOX [32]. Moreover, although adding cetuximab to RT does not change the risk to develop a mucositis in HNC patients compared to RT alone (about $60 \%$ of high grade $\geq 3$ ) [44, 45], however, when it is combined with RT plus CT increases the risk of high grade mucositis generation compared to RT plus CT treatment [46, 47].

Mucositis associated to ado-trastuzumab emtansine (T-DM-1) treatment are referable to a mucosal telangectasia [48]. T-DM-1 regimen is currently approved for HER2+, a member of EGF receptors aberrantly expressed in some tumors, metastatic breast cancer treatment. This treatment promotes a mucosal vascular malformation leading, in the $30 \%$ of patients, to epixastaxis and GI or gynecological bleeding [48, 49].

Oral mucositis, specifically stomatitis characterized by aphthous ulcer, occurs in very few patients treated with cyclin-dependent kinase 4/6 inhibitors (CDK4/6) [50, 51], used as first- or second-line treatment for hormone positive/HER2 negative metastatic breast cancer. However, this regimen promotes GIM rather than OM. Abemaciclib, indeed, induces an early-onset GIM in the first cycles of treatment in about $80 \%$ of the patients [51, 52]. Notably, CDK4/6 inhibitors bind, also, cyclin D3 in GI epithelial cells, inhibiting their proliferation and, consequently, inducing mucosal injury [53].

The BRAF and v-raf murine sarcoma viral oncogene homolog B1 inhibitors, vemurafenib and dafrafenib, have been recently approved by the Food and Drug Administration (FDA) for treatment of metastatic melanoma harboring $\mathrm{BRAF}^{\mathrm{V} 600}$ mutation. Patients treated with one of these inhibitors develop asymptomatic hyperkeratotic lesions rising both in the keratinized and non-keratinized mucosa, including mucosal lesions characterized by a verrucous or papillomatous appearance rising in the tongue, labial mucosa and linea alba [54-56].
Non-specific stomatitis, characterized by oral mucosal hypersensitivity and associated with a moderate erythema or inflammation painful, is described as an adverse event of anti angiogenetic drug treatment [57]. The probability to develop a stomatitis event changes accordingly to the target drug administrated. Indeed, bevacizumab or ramucirumab two monoclonal antibodies directed versus the vascular endothelial growth factor receptor (VEGFR), rarely induce stomatitis. Conversely, $25 \%$ of patients treated with multi- kinase inhibitors (MKIs), such as sunitinib, sorafenib or cabozantinib, complain stomatitis within the first two months of therapy [57]. However, less than the $10 \%$ of them need drug dosage re-modulation, while only $1 \%$ discontinues the treatment [57].

Low grade stomatitis is also described, although in few cases, as immunotherapy-related adverse event (irAE) in patients treated with the anti-programmed death 1 (PD1), pembrolizumab and nivolumab, or anti-programmed death ligand 1 (PDL1) drug, atezolizumab and durvalumab [32]. Patients treated with an immuno-check point drug suffer of different grade of diarrhea often associated to abdominal pain, dehydration and constipation [58, 59]. Endoscopic analysis has revealed presence of colic mucosa with a mild inflammation and/or ulceration upon PD1 or PDL1 treatment, while the same appeared ulcerated and friable in patients treated with a cytotoxic $\mathrm{T}$ lymphocyte-associated antigen 4 (CTLA4) inhibitor [35, 60]. Between the $27-54 \%$ of patients treated with a CTLA4 inhibitor, indeed, complain GI toxicities that often determine either treatment remodulation or discontinuation [61].

\section{Mucositis prevention}

While a growing number of new anti cancer agents are currently in clinical practice, only few therapeutic options are available for mucositis prevention or treatment. Their effectiveness is still poor. Notably, palifermin, a recombinant human keratinocyte growth factor 1 (KGF1 ), is the only drug approved both by FDA and the European Medical Agency (EMA) for OM prevention in patients undergoing high doses CT plus total body RT prior to HSCT [62]. Palifermin acts stimulating epithelial cells proliferation and differentiation, thereby promoting faster tissue regeneration following chemo- and/or radiotherapy-induced damages. Moreover, it has antioxidant and antiapoptotic activities together with an anti pro-inflammatory action. The efficacy of this drug in preventing $\mathrm{OM}$ was also tested in HNC patients. Two different studies have demonstrated that patients treated with palifermin showed a lower incidence of high grade $(\geq 3)$ OM [63, 64], however the high cost and the concerns about the possibility that this drug might sustain cancer cells growth makes it unsuitable for OM management in HNC patients. 
In the following sections, we will resume clinical and pre-clinical evidences on the effectiveness of some of the so far tested drugs for mucositis development prevention grouped accordingly to their mechanism of action. A comprehensive list of drugs is reported in Table 1.

\section{Antioxidant agents}

Mucositis development is a multistep process, accordingly a good therapeutic option should impinge concurrently on different key pathways involved in its pathobiology without affecting the anti neoplastic regimen efficacy. In this regard, ROS, as early drivers of mucosa damage, represent a potential target for the inhibition of mucositis development. Antioxidant agents, such as amifostine, have been found to partially prevent mucositis development during RT treatment, reducing DNA strand breaks and preserving salivary gland, endothelium and connective tissue integrity $[65,66]$. However, the related adverse events and the intravenous administration limit amifostine use in the routine clinical practice.

The administration of other ROS-scavenger drugs such as glutamine [67-71], oral zinc supplement [72-75, 77], vitamin E [78-80] or N-acetyl-cysteine (NAC) [81] have provided contradictorily evidences of their effectiveness in mucositis prevention. Recently, the MASCC/ ISOO panel of experts have suggested the oral administration of glutamine tablets for OM prevention in HNC patients treated with CT-RT therapy. Conversely they have recommended against the parental administration of glutamine for OM prevention in patients undergoing to HSCT regimen due to the higher mortality rate associated to this treatment [108].

A synthetic manganese-based drug, GC4419, is currently investigated in a phase II study for mucositis prevention in HNC patients treated with cisplatin and RT, based on its ability to inhibit ROS production counteracting superoxide dismutase (SOD) activity [83] (clinicaltrials.gov identifier: NCT02508389).

\section{Inhibitors of inflammation and cytokines production}

As previously mentioned, NF- $\mathrm{KB}$ represents the main transcriptional mediator of mucositis process. It directly modulates transcription of several pro-inflammatory cytokines (TNF- $\alpha$; IL- 6 ; IL-1 $\beta$ ) involved in the RT and CTmediated damage signaling amplification $[7,8]$. NF- $\mathrm{kB}$ has been also shown to promote drug resistance mechanisms [109, 110]; thereby the impairment of its action could affect mucositis development and cancer progression, concurrently. In this regard, turmeric, a flowering plant belonging to Curcuma longa of the ginger family, has been found to reduce and delay $\mathrm{OM}$ severity in HNC patients by counteracting NF-kB activity upon RTmediated tissue injury [84]. Likewise, clonidine lauriad mucoadhesive buccal tablets (Clonidine Lauriad ${ }^{\circ}$ ) administration has been found to reduce the percentage of HNC patients developing high-grade mucositis (45.3\% clonidine + CRT arm vs. $60 \%$ placebo + CRT arm), through the direct inhibition of NF- $\mathrm{kB}$ activity and of the downstream pro-inflammatory cytokines-mediated signal [85]. Intriguingly, transgenic mice expressing high levels of Smad7 (K5.Smad7) in oral epithelia resulted more resistant to radiation-induced oral mucositis development than wild type mice [86]. Indeed, high Smad7 levels, impairing concurrently both TGF- $\beta 1$ that NF- $\kappa B$ activities, have been found to inhibit damage-mediated inflammation and promote a quickly epithelia self renewal, thus impairing OM development [86]. However, data obtained from the above reported evidences are very preliminary; further studies are mandatory to provide solid evidences of turmeric and clonidine effectiveness in mucositis prevention, as well as to understand the consequence of Smad7 over-expression on tumor behavior.

Conversely, there is strong evidence supporting the use of benzydamine hydrochloride rinses for OM prevention in HNC patients undergoing to RT, but not for those treated with either CT or CT-RT. Notably, the anti-inflammatory action of benzydamine has been found to inhibit the activity and the production of several pro-inflammatory cytokines, thus to reduce frequency of severe mucositis development (43.6\% in benzydamine arm vs. $78.6 \%$ placebo arm) and percentage of patients developing mucosa erythema or ulceration [87, 88]. Basing on these data, EMA and the Multinational Association of Supportive Care in Cancer and International Society of Oral Oncology (MASCC/ ISOO) guidelines recommend the use of benzydamine rinses in $\mathrm{HNC}$ patients undergoing to moderate-dose RT $(<50 \mathrm{~Gy})$ and suggested the use also for OM prevention in HNC patients who receive RT-CT [108]. Further studies are ongoing to determine the efficacy of benzydamine also in patients managed with high-dose RT.

As well as benzydamine, pentoxifylline acts as antiinflammatory agent inhibiting TNF- $\alpha$ and IL- $1 \beta$. It has been demonstrated to decrease $\mathrm{OM}$ development in mice undergoing to irradiation [89] and, in association with vitamin $\mathrm{E}$, has been found reducing RT-induced OM severity in a small cohort of HNC patients [90].

Dusquetide, SGX942, is an immune defense regulator agent able to modulate immune innate pro-inflammatory response and the subsequently signaling amplification that result over-activated during mucositis development. A randomized phase II study has reported that intravenous duquetide administration in HNC patients treated with CDDP and RT significantly reduced OM duration and rate of infection compared to patients belonging to the placebo arm [91]. Phase III studies, enrolling large cohorts of patients, will definitively support the effectiveness of pentoxifylline and duquetide in $\mathrm{OM}$ prevention. 
Table 1 List of therapies under investigation for mucositis development prevention grouped accordingly to their mechanism of action

\begin{tabular}{|c|c|c|c|}
\hline Antioxidant agents & Characteristics & Mechanism of action & References \\
\hline Amifostine & $\begin{array}{l}\text { Phosphorylated aminosulfhydryl } \\
\text { compound }\end{array}$ & $\begin{array}{l}\text { Promotes recruitment of ROS scavenger, reduces DNA strand } \\
\text { breaks }\end{array}$ & {$[65,66]$} \\
\hline Glutamine & Amino acid & Exerts antioxidant activities promoting glutathione synthesis & {$[67-71]$} \\
\hline Oral zinc supplement & Essential mineral & $\begin{array}{l}\text { Prevents lipids peroxidation, replaces redox reactive metals, } \\
\text { induces metallothionein synthesis }\end{array}$ & [72-77] \\
\hline Vitamin $\mathrm{E}$ & Lipid soluble a-tocopherol & Prevents tissue damages caused by the ROS release & [78-80] \\
\hline $\mathrm{N}$-acetyl-cysteine & $\begin{array}{l}\mathrm{N} \text {-acetyl derivative of the natural amino } \\
\text { acid L-cysteine }\end{array}$ & $\begin{array}{l}\text { Exerts antioxidant activities promoting glutathione synthesis, } \\
\text { myeloperoxidase activity, xanthine dehydrogenase and oxidase } \\
\text { activity. }\end{array}$ & {$[81,82]$} \\
\hline GC4419 & Synthetic manganese-based drug & Counteracts superoxide dismutase activity & [83] \\
\hline $\begin{array}{l}\text { Inhibitors of } \\
\text { inflammation and } \\
\text { cytokines production }\end{array}$ & Characteristics & Mechanism of action & References \\
\hline Turmeric & $\begin{array}{l}\text { Flowering plant belonging to Curcuma } \\
\text { longa }\end{array}$ & Counteracts NF- $\mathrm{KB}$ activiy & [84] \\
\hline $\begin{array}{l}\text { Clonidine lauriad } \\
\text { mucoadhesive buccal } \\
\text { tablets }\end{array}$ & $\begin{array}{l}\text { Tablets contain high concentrations of } \\
\text { an anti-inflammatory active principle } \\
\text { (clonidine) }\end{array}$ & $\begin{array}{l}\text { Inhibits NF-kB activity and the downstream pro-inflammatory } \\
\text { cytokines-mediated signal }\end{array}$ & [85] \\
\hline SMAD7 over expression & $\begin{array}{l}\text { Gene encoding the nuclear protein } \\
\text { Smad7 that binds the E3 ubiquitin ligase } \\
\text { SMURF2 }\end{array}$ & $\begin{array}{l}\text { Impairs TGF- } \beta 1 \text { that NF-KB activities in mice model (K5.Smad7) } \\
\text { irradiated }\end{array}$ & [86] \\
\hline $\begin{array}{l}\text { Benzydamine } \\
\text { hydrochloride rinses }\end{array}$ & $\begin{array}{l}\text { Indazole non-steroidal anti-inflammatory } \\
\text { drug }\end{array}$ & $\begin{array}{l}\text { Inhibits the activity and the production of pro-inflammatory } \\
\text { cytokines, TNF- } \alpha \text { and IL-1 } \beta\end{array}$ & {$[87,88]$} \\
\hline Pentoxifylline & Xanthine derivative & Impairs NF-KB activity and inhibits TNF- $\alpha$ and IL-1 $\beta$ action & {$[89,90]$} \\
\hline Dusquetide (SGX942) & $\begin{array}{l}\text { 5-amino acid innate defence regulator } \\
\text { (IDR) peptide }\end{array}$ & Modulates immune innate pro-inflammatory response & [91] \\
\hline $\begin{array}{l}\text { Multi target natural } \\
\text { agents }\end{array}$ & Characteristics & Mechanism of action & Referenc \\
\hline Honey & Honey topical application & Attenuates burns and pressure wounds. & [92-95] \\
\hline $\begin{array}{l}\text { Manuka and Kanuka } \\
\text { essential oils }\end{array}$ & $\begin{array}{l}\text { Mix of essential oil from Leptospermum } \\
\text { scoparium and Kunzea ericoides }\end{array}$ & $\begin{array}{l}\text { Anti-inflammatory, analgesic and anti-micotic and -bacterial } \\
\text { activities }\end{array}$ & [96] \\
\hline Chinese traditional herbs & $\begin{array}{l}\text { 1-Extract of Indigowood root } \\
\text { 2-Extract of Rhodiola algida }\end{array}$ & $\begin{array}{l}\text { 1-Anti-inflammatory and antiviral activities } \\
\text { 2-Stimulates the immuno system }\end{array}$ & {$[97,98]$} \\
\hline Chamomile mouthwash & infusion of powdered flower in water & $\begin{array}{l}\text { Anti-inflammatory, analgesic and anti-micotic and -bacterial } \\
\text { activities }\end{array}$ & {$[99,100]$} \\
\hline Aloe vera gel & $\begin{array}{l}\text { Juice of succulent plant species of the } \\
\text { genus Aloe }\end{array}$ & Promotes wound healing & [101] \\
\hline MF $5232\left(\right.$ Mucotrol $\left.^{\circledR}\right)$ & Oral poliherbal gel wafer & Analgesic, wound healing and anti oxidant properties & [102] \\
\hline Traumeel $S^{\oplus}$ & Homeophatic complex mouthwash & Unknown mechanism of action & [103] \\
\hline Physical intervention & Characteristics & Mechanism of action & Reference \\
\hline $\begin{array}{l}\text { Low-levels laser therapy } \\
\text { (LLLT) }\end{array}$ & Monochromatic laser at low intensity & Promotes regeneration of damaged-tissue & {$[73,83]$} \\
\hline Oral cryotherapy & ice chips, ice cubes, ice lollipops & $\begin{array}{l}\text { Promotes local vasoconstriction, thus leading to a reduction } \\
\text { exposure of mucosa to chemotherapy }\end{array}$ & $\begin{array}{l}{[73,81,} \\
104]\end{array}$ \\
\hline Oral care & $\begin{array}{l}\text { Standardized oral care and frequent oral } \\
\text { cavity examination by oral care experts }\end{array}$ & Prevents infections & [105] \\
\hline Lactobacillus & Probiotic & Preserves mucosal intestinal architecture & {$[106,107]$} \\
\hline
\end{tabular}

\section{Natural agents}

Compared to most of the above-described drugs, natural compounds can be administrated as dietary supplements.
Accordingly, they are often well tolerated by patients and do not induce severe adverse events. Moreover, thanks to their chemical structure, they can concurrently impinge 
on several cellular signaling pathways thus affecting mucositis pathogenesis process at different levels, as well as negatively impacting on tumorigenic activities of cancer cells $[109,111,112]$. Actually, diverse natural products have been already tested and others are under investigation in active clinical trials. Among the natural agents tested so far, glutamine, vitamin $\mathrm{E}$ and the oral zinc supplement have been the most studied. However, as previously discussed, the provided data are contradictory and do not support their administration for mucositis prevention [17, 81, 113]. Moreover, the promising data are often limited by the small numbers of enrolled patients and/or by the absence of a standardized methodological protocol for compound manufacturing. This is the case of the essential oils of manuka (Leptospermum scoparium) and kanuka (Kunzea ericoides), whose wound healing, anti-inflammatory, analgesic and anti-micotic and -bacterial properties seem to be effective in OM prevention, as well as the administration of chinese herbal drugs (Indigowood root or $R$. algida), chamomile or aloe vera [113]. Conversely, the systemic topical honey administration is suggested in HNC patients treated with either RT or CTRT to prevent OM development. [108]. A detailed list of multi target natural agents is reported in Table 1.

\section{Physical intervention}

Low level application of monochromatic laser and low level laser therapy (LLLT), also called photobiomodulation, applied locally have shown to promote healing of the damage tissue and to inhibit inflammation in animal models $[114,115]$. Several clinical studies have further demonstrated the efficacy of LLLT in reducing mucositis severity through the regeneration of damaged-tissue both in patients undergoing chemo-radiotherapy before HSCT [73] that in HNC patients managed with only RT [83]. For those reasons, LLLT application is recommended for OM prevention in the setting of HSCT regimen by MASCC/ISOO guidelines [108]. The same association suggests the use of LLLT application for HNC patients undergoing to CT plus RT or RT only [108]. However, although clinical evidences support the application of this technique in HNC patients, there are in vitro evidences that revealed how LLLT can trigger pro-tumorigenic signaling pathways in tumor cells [114, 116-118]. Accordingly, further studies are mandatory to define a specific guideline for a correct use of LLLT in patients affected by solid tumors. In general, it is recommended to not apply directly low-levels laser impulse on cancer tissue, as well as a strict patient vigilance [83].

MASCC/ISOO guidelines recommend oral cryotherapy use 30 minutes before 5-FU bolus administration, as well as in patients undergoing to autologous HSCT regimen with the presence of high dose of melphalan [108]. The use of ice chips, or ice cubes, or ice lollipops are, indeed, associated with a reduction in 5-FU-mediated OM incidence and severity [73, 81]. Cryotherapy application promotes local vasoconstriction, thus leading to a reduction exposure of mucosa to 5-FU [104].

\section{Oral care and probiotics}

Although there is no strong evidences of its efficacy for OM prevention, a standardize oral care is suggested by the MASCC / ISOO guidelines [108]. A healthy oral hygiene, indeed, leads to positive benefits, preventing, at least in part, either infections or sepsis events during mucosa ulceration. Besides, a frequent oral cavity examination by oral care experts, before and during anti cancer therapy, could reduce infection risk, as well as could be helpful to reveal earlier mucositis development [105].

Pre-clinical evidences have showed that probiotic administration preserves mucosal intestinal architecture preventing its disaggregation upon damage injury [107]. Accordingly, an active trial aims to test the protective role of Lactobacillus in preventing irinotecan-induced diarrhea (ClinicalTrials.gov Identifier: NCT02819960) [106]. Recently, MASCC / ISOO guidelines have suggested the use of Lactobacillus probiotics to prevent diarrhea in patients with pelvic malignancy treated with RT or RT plus CT [108].

\section{Mucositis-related symptoms treatment}

Mucositis-associated pain severely affects patient quality of life. High-grade mucositis often cause an inadequate food intake; consequently, patients can develop serious nutritional deficiency and need parenteral nutrition. Moreover, about the $15 \%$ of them experience a premature therapy termination or a dosage re-modulation, thus affecting survival. Consequently, treatment of pain associated to mucositis is pivotal for cancer patient clinical management.

Analgesics are the most administrated drugs for OMassociated pain control. Morphine is, indeed, recommended by MASCC/ISOO guidelines for OM-associated pain caused by CT and RT treatment in patients undergoing hematopoietic stem cell transplant [119]. Mouth rinses or washes with formula containing morphine are also administrated in $\mathrm{HNC}$ patients developing high grade OM. Besides, several "magic" mouthwashes for patients pain control have been formulated. They usually contain anesthetic, antacid and diphenhydramine; sometimes steroids and anti-micotics [83]. A pilot study of 26 HNC patients undergoing to RT plus CT has revealed that patients who managed $\mathrm{OM}$-associated pain with mouthwashes containing $0.2 \%$ of morphine complained a shorter duration of severe pain and required lower systemic analgesic administration than that administered to patients who used the magic formulation (lidocaine, magnesium aluminum hydroxide, diphenhydramine) for 
oral rinses [120]. Topical $0.2 \%$ morphine mouthwashes are suggested by MASCC/ISOO guidelines for HNC patients with $\mathrm{OM}$ caused by concomitant radio- and chemotherapy [108].

The mucositis study group of MASCC/ISOO has evaluated the effectiveness of additional agents, but the reported data so far did not allow their use for OMassociated pain management. It is the case of chlorhexidine mouthwashes, caphasol re-mineralizing solution rinses or application of topical coating agents [108, 119], such as MuGard whose properties have been evaluated in a multicenter trial reporting only palliative effects [121].

Application of sucralfate enemas, acting as a protective barrier, is suggested for rectal bleeding management caused by RT-induced proctitis; while loperamide, an opioid-receptor agonist, or octreotide, a somatostatin analogue used when loperamide treatment failed, is recommended for diarrhea control in patients undergoing RT plus CT before HSCT [119].

\section{Biomarker feasibility for oral mucositis development risk assessment and early diagnosis}

The opportunity to stratify cancer patients according to their risk to develop mucositis, as well as the possibility to identify mucositis development and its severity in an early phase represents an unmet need for researchers and clinicians. Identification of a standardized biomarker for mucositis assessment and/or early diagnosis might allow, indeed, a precision management of patient, thus reducing hospitalization, therapy termination and dosage re-modulation; ultimately reducing patient management cost. Costs to care a HNC patient who develops highgrade mucositis, indeed, can rise from $2,000 \$$ up to 6 , $000 \$$ in the United States [122].

Cytokines that are released after the chemo- and/or radio-mediated tissue primary injury, act as signal transducers leading to amplification of damage response. Based on their functions and properties, several authors have investigated the feasibility to correlate their levels with mucositis severity and/or mucositis early diagnosis. However, data provided so far are controversial. For instance, TNF- $\alpha$ levels have been found either high [123, 124] or low $[125,126]$ during RT in different studies, while only one report has shown a significant correlation between TNF- $\alpha$ levels and OM severity [124] (Table 2).

The same controversial results have been provided by studies that correlated IL-10 and IL-1 levels and OM in HNC patients undergoing to CT or/and RT [123, 125, 126] (Table 2). Further evidences are mandatory to confirm the correlation between high-grade mucositis development and IL-6 or IL-1 $\beta$ levels in RT treated patients [123-125] (Table 2).
High levels of TGF- $\beta$ have been found in the plasma of patients experiencing a RT-induced severe toxicity $[127,128]$. However, while TGF- $\beta$ concentration increased in response to RT, it did not correlate with risk of mucositis development $[127,128]$. Conversely, plasma levels of the epidermal growth factor (EGF) negatively correlated with risk of OM development. Indeed, HNC patients with low levels of EGF before treatment exhibited a major risk to develop OM during RT [129-131] (Table 2).

The feasibility to use markers of the so call "inflammatory acute phase" as mucositis biomarkers has been also evaluated. The C-reactive protein (CRP) and the erythrocyte sedimentation rate (ESR) are two important markers which assessment is routinely done to diagnose the presence of an inflammation process through blood test. Their levels have been found high in the blood of patients at the end of RT [132-135]. Notably, Ki et al., have found a correlation between the increase in CRP, but not ESR, levels and mucositis progression [132], while Chethana et al., have found a correlation between OM and CRP levels only in the first weeks of treatment [135] (Table 2).

Sporadic studies have evaluated a putative correlation between the OM development and/or severity and the levels of different proteins usually involved in processes such as apoptosis, ROS scavenger, adhesion and structural proteins. In particular, high levels of p53 [124], BPI Fold Containing Family A Member 1 (BPIFA-1) [140], Intercellular Adhesion Molecule 1 (ICAM-1), E-selectin, Lymphocyte function-associated antigen 1 (LFA-1) and macrophage integrin (Mac-1) have been found in presence of high-grade mucositis [141]. Conversely, low levels of pro-apoptotic proteins such as the B-cell lymphoma 2 (BCL-2) and the induced myeloid leukemia cell differentiation protein (Mcl-1) [124], as well as low levels of antioxidant glutathione GSH have been reported [136]. Notably, meta-analysis conducted by Normando and colleagues have collected and analyzed this evidence without finding a strong correlation between the levels of the previous cited proteins and OM process [142]. The heterogeneity of the analyzed studies and the low numbers of enrolled patients, indeed, do not allow their dosage for mucositis prediction [142]. The specificity of these proteins for OM assessment should be further investigated.

As reported above, radiotherapy directly injures mucosa provoking double strand breaks (DSBs) of DNA. Accordingly, a reduction in the activities of key proteins involved in the DNA repair could correlate with mucositis incidence and/or with its severity. Among them, the histone protein $\gamma$-H2AX levels correlated with radiotherapyinduced toxicities, such as oral mucositis [138, 139] (Table 2). Moreover, the efficiency in DSBs repair can 
Table $\mathbf{2}$ List of proteins tested as biomarkers of mucositis development and/or severity

\begin{tabular}{|c|c|c|c|c|c|c|}
\hline Biomarker & Reference & Treatment & Disease & Origin & $\begin{array}{l}\text { Levels during } \\
\text { treatment }\end{array}$ & Significant association with OM \\
\hline \multirow[t]{4}{*}{ TNF-a } & {$[123]$} & RT & $\mathrm{HNC}$ & Saliva & High & No \\
\hline & [124] & RT & $\mathrm{HNC}$ & $\begin{array}{l}\text { Cytologic smears } \\
\text { from oral cavity }\end{array}$ & High & Association with OM development \\
\hline & {$[125]$} & $\mathrm{RT}, \mathrm{RT}+\mathrm{CT}$ & HNC & Serum & Low & No \\
\hline & [126] & $\mathrm{RT}, \mathrm{RT}+\mathrm{CT}$ & $\mathrm{HNC}$ & Serum & Low & No \\
\hline \multirow[t]{2}{*}{ IL-1 } & [125] & $\mathrm{RT}, \mathrm{RT}+\mathrm{CT}$ & $\mathrm{HNC}$ & Serum & No change & No \\
\hline & [126] & $\mathrm{RT}, \mathrm{RT}+\mathrm{CT}$ & $\mathrm{HNC}$ & Serum & No change & No \\
\hline IL-1 $\beta$ & {$[124]$} & RT & $\mathrm{HNC}$ & $\begin{array}{l}\text { Cytologic smears } \\
\text { from oral cavity }\end{array}$ & High & Association with OM development \\
\hline \multirow[t]{2}{*}{ IL-6 } & [123] & RT & $\mathrm{HNC}$ & Saliva & High & Association with OM severity \\
\hline & [125] & $\mathrm{RT}, \mathrm{RT}+\mathrm{CT}$ & $\mathrm{HNC}$ & Serum & High & Association with OM severity \\
\hline \multirow[t]{2}{*}{ IL-8 } & [123] & RT & $\mathrm{HNC}$ & Saliva & High & No \\
\hline & {$[125]$} & $\mathrm{RT}, \mathrm{RT}+\mathrm{CT}$ & $\mathrm{HNC}$ & Serum & High & No \\
\hline \multirow[t]{2}{*}{ IL-10 } & [123] & RT & $\mathrm{HNC}$ & Saliva & High & Association with OM severity \\
\hline & {$[125]$} & $\mathrm{RT}, \mathrm{RT}+\mathrm{CT}$ & $\mathrm{HNC}$ & Serum & No change & No \\
\hline TGF- $\beta$ & {$[127,128]$} & $\mathrm{RT}+\mathrm{CT}$ & $\mathrm{HNC}$ & Plasma & High & Association with OM severity \\
\hline \multirow[t]{2}{*}{ EGF } & {$[2,129,130]$} & RT & $\mathrm{HNC}$ & Saliva & Low & Association with OM development \\
\hline & [131] & RT & $\mathrm{HNC}$ & Saliva & Low & Association with OM development \\
\hline \multirow[t]{4}{*}{ CRP } & [132] & RT & $\mathrm{HNC}$ & Blood & High & Association with OM severity \\
\hline & [133] & RT & $\mathrm{HNC}$ & Blood & High & Not assessed \\
\hline & {$[134]$} & $\mathrm{RT}, \mathrm{RT}+\mathrm{CT}$ & $\mathrm{HNC}$ & Blood & High & Not assessed \\
\hline & [135] & $\mathrm{RT}+\mathrm{CT}$ & $\mathrm{HNC}$ & Blood & High & $\begin{array}{l}\text { Association with OM severity only } \\
\text { at initial week }\end{array}$ \\
\hline \multirow[t]{3}{*}{ ESR } & [132] & RT & $\mathrm{HNC}$ & Blood & High & No \\
\hline & [134] & $\mathrm{RT}, \mathrm{RT}+\mathrm{CT}$ & $\mathrm{HNC}$ & Blood & High & Not assessed \\
\hline & [135] & $\mathrm{RT}+\mathrm{CT}$ & $\mathrm{HNC}$ & Blood & High & No \\
\hline \multirow[t]{2}{*}{ GSH } & [136] & RT & $\begin{array}{l}\text { Oral cavity } \\
\text { cancer }\end{array}$ & Plasma & $\begin{array}{l}\text { Measured } \\
\text { before RT }\end{array}$ & $\begin{array}{l}\text { GSH baseline levels associate with } \\
\text { OM development }\end{array}$ \\
\hline & [137] & RT & $\mathrm{HNC}$ & Plasma & No change & No \\
\hline \multirow[t]{2}{*}{$\begin{array}{l}\text { DNA DSB } \\
(\gamma-\mathrm{H} 2 A X)\end{array}$} & [138] & RT & $\mathrm{HNC}$ & $\begin{array}{l}\text { Peripheral blood } \\
\text { lymphocytes }\end{array}$ & High & Association with OM severity \\
\hline & [139] & $R T, R T+C T$ & $\mathrm{HNC}$ & $\begin{array}{l}\text { Peripheral blood } \\
\text { lymphocytes }\end{array}$ & High & No \\
\hline
\end{tabular}

change among patients basing on the presence of singlenucleotide polymorphisms (SNPs) in the sequence of genes involved in this process. Indeed, presence of specific SNPs modulates activities of the related translated protein [143]. It is the case of some SNPs harbored in genes such as XRCC1, XRCC3 and RAD51, which activities are critical during the DNA repair. Their presence has been related to an increased risk to develop radiotherapy mediated toxicities [144-146]. However, the correlation with $\mathrm{OM}$ is not so strong [142]; further studies are needed to support their assessment for OM development.

In 2017, Gutierrez-Camino and colleagues have identified a significant correlation between the presence of SNP rs10505168 in the sequence of miR-2053 and an increased risk to develop $\mathrm{OM}$ in children undergoing methotrexate treatment for pediatric acute lymphoblastic leukemia (ALL) treatment [147].

Recently, Laheji and colleagues have undertaken oral microbioma analysis from patients undergoing to CT plus RT treatment before autologous hematopoietic stem cell transplantation and revealed that patients who did not develop an ulcerative OM exhibited more resilient microbioma than those patients developing an ulcerative OM [148].

As previously described, most of the so far tested biomarkers require further studies to be validated either for mucositis diagnosis or for mucositis severity prediction. A standardized protocol for their assessment, as well as 
strict criteria of patient enrolment are mandatory to clinically validate their use as biomarkers. However, these aspects may not be enough, the main bias, indeed, is that none of them is a specific marker that characterizes mucositis process. They are, indeed, produced as consequence of different stresses. That aspect could compromise their feasibility as mucositis biomarkers. During antineoplastic treatment, the whole organism undergoes to several stresses that could either hide or mimic mucositis process. It could be helpful to find a marker that specifically identifies mucositis process development. Non-coding RNAs have been found to be more lineage-specific than protein coding genes, unveiling how their different expression might specifically determine cell phenotype [149-151]. Accordingly, this may not be foolish the research of non-coding RNAs that are specifically involved in mucositis process, whose assessment could be used as mucositis biomarker.

\section{Conclusions}

The advance in cancer therapies has significantly improved survival of patients. However, while therapies become increasingly effective, only few valid options are available for antineoplastic therapy-induced oral mucositis treatment or prevention; which often cause either treatment premature termination or re-modulation. This also increases hospitalization with a consequently increase of cost for public health and reduction of the patient quality of life. The opportunity to identify patient susceptibility to develop OM, through an accessible and non-invasive test assessing of OM-related specific biomarkers expression, might allow to design a personalized targeted treatment. This might also allow testing the prevention activity of new agents in a high-risk sub population, thus improving the significance of the clinical outcome.

Nowadays, oral mucositis still remains an underestimated side effect of anticancer therapy. The synergistic efforts of basic, translational and clinical scientists is strongly required to improve cancer patients quality of life and, consequently, reduce their management cost.

\section{Abbreviations}

CT: Chemotherapy; RT: radiotherapy; GIM: gastro-instestinal mucositis: OM: oral mucositis; HSCT: hemopoietic stem cell transplantation; HNC: head and neck cancer; 5-FU: 5-Fluoruracil; WHO: World Health Organization; OMAS: Oral Mucositis Assessment Scale; ECOG: Eastern Cooperative Oncology Group; NCl: National Cancer Institute; JNK: Common Terminology Criteria for Adverse kinase; NRF2: erythroid 2-related factor 2; AP1: activating protein-1; MMP: metalloproteinase; MAPK: mitogen activated protein kinase; TGF: tumor growth factor; mIAS: mTOR-inhibitor-associated stomatitis; RCC: renal cell carcinoma; EGFR: epidermal growth factor; TKi: tyrosine kinase inhibitor; T-DM-1: ado-trastuzumab emtansine; CDK4/6: cyclin-dependent kinase 4/6 inhibitors; FDA: Food and Drug Administration; VEGFR: vascular endothelial growth factor receptor; irAE: immunotherapy-related adverse event; PDL1: anti-programmed death ligand 1; PD1: anti-programmeddeath 1: CTLA4: cytotoxic T lymphocyte-associated antigen 4; KGF-1: keratinocyte growth factor 1; EMA: European Medical Agency; NAC: N-acetyl-cysteine;
SOD: superoxide dismutase; MASCC/ISOO: Multinational Association of Supportive Care in Cancer and International Society of Oral Oncology; LLLT: low-levels laser therapy; CRP: C-reactive protein; ESR: erythrocyte sedimentation rate; BPIFA-1: BPI Fold Containing Family A Member 1; ICAM1: Intercellular Adhesion Molecule 1; LFA-1: Iymphocyte function associated antigen 1; Mac-1: macrophage integrin; BCL-2: B-cell lymphoma 2; Mcl-1: induced myeloid leukemia cell differentiation protein; DSBs: double strand breaks; SNPs: single-nucleotide polymorphisms; ALL: acute lymphoblastic leukemia

\section{Acknowledgements}

Not applicable.

\section{Authors' contributions}

$\mathrm{CP}, \mathrm{GB}$ and SS contributed to conceive, design and revision of the manuscript sections, CP, GB and SS wrote the manuscript, CP designed Fig. 1 and created Tables 1 and 2. AC provided Fig. 2. AC, CLP, SZ GB, AM and SS supervised the manuscript by providing critical feedbacks and revisions. The authors read and approved the final manuscript.

\section{Funding}

GB acknowledges the support of AIRC IG 2017 ID 20613, Lazio Innova/ Regione Lazio, MAECI Italy/USA bilateral grant program and Alliance Against Cancer (ACC). AM acknowledges the Italian Health office for grant support.

Availability of data and materials

Not applicable.

Ethics approval and consent to participate

Not applicable.

\section{Consent for publication}

Not applicable.

\section{Competing interests}

The authors declare that they have no competing interests.

\section{Author details}

${ }^{1}$ Oncogenomic and Epigenetic Unit, IRCCS, Regina Elena National Cancer Institute, Rome, Italy. ${ }^{2}$ STI/HIV Unit, San Gallicano Dermatological Institute IRCCS, Rome, Italy. ${ }^{3}$ Center for Complexity and Biosystems, Department of Environmental Science and Policy, University of Milan, via Celoria 26, 20133 Milano, Italy. ${ }^{4} \mathrm{CNR}$ - Consiglio Nazionale delle Ricerche, Istituto di Biofisica, via Celoria 26, 20133 Milano, Italy. ${ }^{5}$ Center for Complexity and Biosystems, Department of Physics, University of Milan, Via Celoria 16, 20133 Milano, Italy. ${ }^{6}$ CNR - Consiglio Nazionale delle Ricerche, Istituto di Chimica della Materia Condensata e di Tecnologie per l'Energia, Via R. Cozzi 53, 20125 Milano, Italy. ${ }^{7}$ Scientific Director Office, San Gallicano Institute, Rome, Italy. ${ }^{8}$ SAFU Laboratory, Department of Research, Advanced Diagnostic, and

Technological Innovation, IRCCS, Regina Elena National Cancer Institute, Via Elio Chianesi, 53, 00144 Rome, Italy.

Received: 22 July 2020 Accepted: 21 September 2020

Published online: 07 October 2020

\section{References}

1. Villa A, Sonis ST. Pharmacotherapy for the management of cancer regimenrelated oral mucositis. Expert Opin Pharmacother. 2016;17:1801-7.

2. Chansky K, Benedetti J, Macdonald JS. Differences in toxicity between men and women treated with 5 -fluorouracil therapy for colorectal carcinoma. Cancer. 2005;103:1165-71.

3. Sloan JA, Goldberg RM, Sargent DJ, Vargas-Chanes D, Nair S, Cha SS, et al. Women experience greater toxicity with fluorouracil-based chemotherapy for colorectal cancer. J Clin Oncol. 2002;20:1491-8.

4. Lalla RV, Sonis ST, Peterson DE. Management of oral mucositis in patients who have cancer. Dent Clin North Am 2008, 52:61-77, viii.

5. Sonis ST. The pathobiology of mucositis. Nat Rev Cancer. 2004;4:277-84

6. Manakova S, Puttonen KA, Raasmaja A, Mannisto PT. Ara-C induces apoptosis in monkey fibroblast cells. Toxicol In Vitro. 2003;17:367-73. 
7. Logan RM, Stringer AM, Bowen JM, Gibson RJ, Sonis ST, Keefe DM. Serum levels of NFkappaB and pro-inflammatory cytokines following administration of mucotoxic drugs. Cancer Biol Ther. 2008;7:1139-45.

8. Logan RM, Stringer AM, Bowen JM, Yeoh AS, Gibson RJ, Sonis ST, et al. The role of pro-inflammatory cytokines in cancer treatment-induced alimentary tract mucositis: pathobiology, animal models and cytotoxic drugs. Cancer Treat Rev. 2007;33:448-60.

9. Davis RJ. Signal transduction by the JNK group of MAP kinases. Cell. 2000; 103:239-52.

10. Braun S, Hanselmann C, Gassmann MG, auf dem Keller U, Born-Berclaz C, Chan $\mathrm{K}$, et al. Nrf2 transcription factor, a novel target of keratinocyte growth factor action which regulates gene expression and inflammation in the healing skin wound. Mol Cell Biol. 2002;22:5492-505.

11. Bamba S, Andoh A, Yasui H, Araki Y, Bamba T, Fujiyama Y. Matrix metalloproteinase-3 secretion from human colonic subepithelial myofibroblasts: role of interleukin-17. J Gastroenterol. 2003;38:548-54.

12. Sasaki M, Kashima M, Ito T, Watanabe A, Izumiyama N, Sano M, et al. Differential regulation of metalloproteinase production, proliferation and chemotaxis of human lung fibroblasts by PDGF, interleukin-1 beta and TNFalpha. Mediators Inflamm. 2000;9:155-60.

13. Bian L, Han G, Zhao CW, Garl PJ, Wang XJ. The role of Smad7 in oral mucositis. Protein Cell. 2015;6:160-9.

14. Alikhani M, Alikhani Z, He H, Liu R, Popek BI, Graves DT. Lipopolysaccharides indirectly stimulate apoptosis and global induction of apoptotic genes in fibroblasts. J Biol Chem. 2003;278:52901-8

15. Engels-Deutsch M, Pini A, Yamashita Y, Shibata Y, Haikel Y, Scholler-Guinard $M$, et al. Insertional inactivation of pac and $\mathrm{rm} \mid \mathrm{B}$ genes reduces the release of tumor necrosis factor alpha, interleukin-6, and interleukin-8 induced by Streptococcus mutans in monocytic, dental pulp, and periodontal ligament cells. Infect Immun. 2003;71:5169-77.

16. Mougeot JC, Stevens CB, Morton DS, Brennan MT, Mougeot FB. Oral Microbiome and Cancer Therapy-Induced Oral Mucositis. J Natl Cancer Inst Monogr. 2019;53:Igz002.

17. Sonis ST. Pathobiology of mucositis. Semin Oncol Nurs. 2004;20:11-5.

18. Abdel-Rahman O, ElHalawani H, Essam-Eldin S. S-1-based regimens and the risk of oral and gastrointestinal mucosal injury: a meta-analysis with comparison to other fluoropyrimidines. Expert Opin Drug Saf. 2016;15:5-20.

19. Keefe DM, Elting LS, Nguyen HT, Grunberg SM, Aprile G, Bonaventura A, et al. Risk and outcomes of chemotherapy-induced diarrhea (CID) among patients with colorectal cancer receiving multi-cycle chemotherapy. Cancer Chemother Pharmacol. 2014;74:675-80.

20. Ribeiro RA, Wanderley CW, Wong DV, Mota JM, Leite CA, Souza MH, et al. Irinotecan- and 5-fluorouracil-induced intestinal mucositis: insights into pathogenesis and therapeutic perspectives. Cancer Chemother Pharmacol. 2016:78:881-93

21. Yamamoto H, Ishihara K, Takeda Y, Koizumi W, Ichikawa T. Changes in the mucus barrier during cisplatin-induced intestinal mucositis in rats. Biomed Res Int 2013, 2013:276186.

22. Hartmann JT, Lipp HP. Toxicity of platinum compounds. Expert Opin Pharmacother. 2003;4:889-901.

23. Pico JL, Avila-Garavito A, Naccache P. Mucositis. Its Occurrence, Consequences, and Treatment in the Oncology Setting. Oncologist. 1998;3:446-51.

24. Trotti A, Bellm LA, Epstein JB, Frame D, Fuchs HJ, Gwede CK, et al. Mucositis incidence, severity and associated outcomes in patients with head and neck cancer receiving radiotherapy with or without chemotherapy: a systematic literature review. Radiother Oncol. 2003;66:253-62.

25. Sanguineti G, Sormani MP, Marur S, Gunn GB, Rao N, Cianchetti M, et al. Effect of radiotherapy and chemotherapy on the risk of mucositis during intensity-modulated radiation therapy for oropharyngeal cancer. Int J Radiat Oncol Biol Phys. 2012;83:235-42.

26. Bonner JA, Giralt J, Harari PM, Baselga J, Spencer S, Bell D, et al. Association of human papillomavirus and p16 status with mucositis and dysphagia for head and neck cancer patients treated with radiotherapy with or without cetuximab: Assessment from a phase 3 registration trial. Eur J Cancer. 2016;64:1-11.

27. Bossi P, Bergamini C, Miceli R, Cova A, Orlandi E, Resteghini C, et al. Salivary Cytokine Levels and Oral Mucositis in Head and Neck Cancer Patients Treated With Chemotherapy and Radiation Therapy. Int J Radiat Oncol Biol Phys. 2016;96:959-66.

28. Villa A, Sonis ST. Mucositis: pathobiology and management. Curr Opin Oncol. 2015;27:159-64.
29. Bossi P, Lucchesi M, Antonuzzo A. Gastrointestinal toxicities from targeted therapies: measurement, duration and impact. Curr Opin Support Palliat Care. 2015;9:163-7.

30. Elting LS, Chang YC, Parelkar P, Boers-Doets CB, Michelet M, Hita G, et al. Risk of oral and gastrointestinal mucosal injury among patients receiving selected targeted agents: a meta-analysis. Support Care Cancer. 2013;21: 3243-54.

31. Sonis ST. Regimen-related gastrointestinal toxicities in cancer patients. Curr Opin Support Palliat Care. 2010;4:26-30.

32. Vigarios E, Epstein JB, Sibaud V. Oral mucosal changes induced by anticancer targeted therapies and immune checkpoint inhibitors. Support Care Cancer. 2017;25:1713-39.

33. Shameem R, Lacouture M, Wu S. Incidence and risk of high-grade stomatitis with mTOR inhibitors in cancer patients. Cancer Invest. 2015;33:70-7.

34. Abdel-Rahman O, Fouad M. Risk of oral and gastrointestinal mucosal injury in patients with solid tumors treated with everolimus, temsirolimus or ridaforolimus: a comparative systematic review and meta-analysis. Expert Rev Anticancer Ther. 2015;15:847-58.

35. Basile D, Di Nardo P, Corvaja C, Garattini SK, Pelizzari G, Lisanti C, et al. Mucosal Injury during Anti-Cancer Treatment: From Pathobiology to Bedside. Cancers (Basel). 2019;11:857.

36. Lacouture ME, Anadkat MJ, Bensadoun RJ, Bryce J, Chan A, Epstein JB, et al. Clinical practice guidelines for the prevention and treatment of EGFR inhibitorassociated dermatologic toxicities. Support Care Cancer. 2011;19:1079-95.

37. Cunningham D, Humblet $Y$, Siena S, Khayat D, Bleiberg $H$, Santoro A, et al. Cetuximab monotherapy and cetuximab plus irinotecan in irinotecanrefractory metastatic colorectal cancer. N Engl J Med. 2004;351:337-45.

38. Price TJ, Peeters M, Kim TW, Li J, Cascinu S, Ruff P, et al. Panitumumab versus cetuximab in patients with chemotherapy-refractory wild-type KRAS exon 2 metastatic colorectal cancer (ASPECCT): a randomised, multicentre, open-label, non-inferiority phase 3 study. Lancet Oncol. 2014;15:569-79.

39. Shepherd FA, Rodrigues Pereira J, Ciuleanu T, Tan EH, Hirsh V, Thongprasert $\mathrm{S}$, et al. Erlotinib in previously treated non-small-cell lung cancer. N Engl J Med. 2005:353:123-32

40. Geyer CE, Forster J, Lindquist D, Chan S, Romieu CG, Pienkowski T, et al. Lapatinib plus capecitabine for HER2-positive advanced breast cancer. N Engl J Med. 2006;355:2733-43.

41. Park K, Tan EH, O'Byrne K, Zhang L, Boyer M, Mok T, et al. Afatinib versus gefitinib as first-line treatment of patients with EGFR mutation-positive nonsmall-cell lung cancer (LUX-Lung 7): a phase 2B, open-label, randomised controlled trial. Lancet Oncol. 2016;17:577-89.

42. Ramalingam SS, Janne PA, Mok T, O'Byrne K, Boyer MJ, Von Pawel J, et al. Dacomitinib versus erlotinib in patients with advanced-stage, previously treated non-small-cell lung cancer (ARCHER 1009): a randomised, doubleblind, phase 3 trial. Lancet Oncol. 2014;15:1369-78.

43. Soria JC, Felip E, Cobo M, Lu S, Syrigos K, Lee KH, et al. Afatinib versus erlotinib as second-line treatment of patients with advanced squamous cell carcinoma of the lung (LUX-Lung 8): an open-label randomised controlled phase 3 trial. Lancet Oncol. 2015;16:897-907.

44. Bonner JA, Harari PM, Giralt J, Cohen RB, Jones CU, Sur RK, et al. Radiotherapy plus cetuximab for locoregionally advanced head and neck cancer: 5-year survival data from a phase 3 randomised trial, and relation between cetuximab-induced rash and survival. Lancet Oncol. 2010;11:21-8.

45. Bonner JA, Harari PM, Giralt J, Azarnia N, Shin DM, Cohen RB, et al. Radiotherapy plus cetuximab for squamous-cell carcinoma of the head and neck. N Engl J Med. 2006;354:567-78.

46. Maddalo M, Borghetti P, Tomasini D, Corvo R, Bonomo P, Petrucci A, et al. Cetuximab and Radiotherapy Versus Cisplatin and Radiotherapy for Locally Advanced Head and Neck Cancer: Long Term Survival and Toxicity Outcomes of a Randomized Phase li Trial. Int J Radiat Oncol Biol Phys. 2020; 107:469-77.

47. Magrini SM, Buglione M, Corvo R, Pirtoli L, Paiar F, Ponticelli P, et al. Cetuximab and Radiotherapy Versus Cisplatin and Radiotherapy for Locally Advanced Head and Neck Cancer: A Randomized Phase II Trial. J Clin Oncol. 2016;34:427-35.

48. Sibaud V, Niec RE, Schindler K, Busam KJ, Roche H, Modi S, et al. Adotrastuzumab emtansine-associated telangiectasias in metastatic breast cancer: a case series. Breast Cancer Res Treat. 2014;146:451-6.

49. Sibaud V, Vigarios E, Combemale P, Lamant L, Lacouture ME, Lacaze JL, et al. T-DM1-related telangiectasias: a potential role in secondary bleeding events. Ann Oncol. 2015;26:436-7. 
50. Lasheen S, Shohdy KS, Kassem L, Abdel-Rahman O. Fatigue, alopecia and stomatitis among patients with breast cancer receiving cyclin-dependent kinase 4 and 6 inhibitors: a systematic review and meta-analysis. Expert Rev Anticancer Ther. 2017;17:851-6.

51. Sledge GW Jr, Toi M, Neven P, Sohn J, Inoue K, Pivot X, et al. MONARCH 2: Abemaciclib in Combination With Fulvestrant in Women With HR+/HER2Advanced Breast Cancer Who Had Progressed While Receiving Endocrine Therapy. J Clin Oncol. 2017;35:2875-84.

52. Dickler MN, Tolaney SM, Rugo HS, Cortes J, Dieras V, Patt D, et al. MONARCH 1, A Phase II Study of Abemaciclib, a CDK4 and CDK6 Inhibitor, as a Single Agent, in Patients with Refractory HR(+)/HER2(-) Metastatic Breast Cancer. Clin Cancer Res. 2017;23:5218-24.

53. Xu H, Yu S, Liu Q, Yuan X, Mani S, Pestell RG, et al. Recent advances of highly selective CDK4/6 inhibitors in breast cancer. J Hematol Oncol. 2017;10:97.

54. Boussemart L, Routier E, Mateus C, Opletalova K, Sebille G, Kamsu-Kom N, et al. Prospective study of cutaneous side-effects associated with the BRAF inhibitor vemurafenib: a study of 42 patients. Ann Oncol. 2013;24:1691-7.

55. Gencler B, Gonul M. Cutaneous Side Effects of BRAF Inhibitors in Advanced Melanoma: Review of the Literature. Dermatol Res Pract 2016, 2016:5361569.

56. Lacouture ME, Duvic M, Hauschild A, Prieto VG, Robert C, Schadendorf D, et al. Analysis of dermatologic events in vemurafenib-treated patients with melanoma. Oncologist. 2013;18:314-22.

57. Yuan A, Kurtz SL, Barysauskas CM, Pilotte AP, Wagner AJ, Treister NS. Oral adverse events in cancer patients treated with VEGFR-directed multitargeted tyrosine kinase inhibitors. Oral Oncol. 2015;51:1026-33.

58. Collins LK, Chapman MS, Carter JB, Samie FH. Cutaneous adverse effects of the immune checkpoint inhibitors. Curr Probl Cancer. 2017;41:125-8.

59. Hofmann L, Forschner A, Loquai C, Goldinger SM, Zimmer L, Ugurel S, et al. Cutaneous, gastrointestinal, hepatic, endocrine, and renal side-effects of anti-PD-1 therapy. Eur J Cancer. 2016;60:190-209.

60. Marthey L, Mateus C, Mussini C, Nachury M, Nancey S, Grange F, et al. Cancer Immunotherapy with Anti-CTLA-4 Monoclonal Antibodies Induces an Inflammatory Bowel Disease. J Crohns Colitis. 2016;10:395-401.

61. Gupta A, De Felice KM, Loftus EV Jr, Khanna S. Systematic review: colitis associated with anti-CTLA-4 therapy. Aliment Pharmacol Ther. 2015;42: 406-17.

62. Spielberger R, Stiff P, Bensinger W, Gentile T, Weisdorf D, Kewalramani T, et al. Palifermin for oral mucositis after intensive therapy for hematologic cancers. N Engl J Med. 2004;351:2590-8.

63. Henke M, Alfonsi M, Foa P, Giralt J, Bardet E, Cerezo L, et al. Palifermin decreases severe oral mucositis of patients undergoing postoperative radiochemotherapy for head and neck cancer: a randomized, placebocontrolled trial. J Clin Oncol. 2011;29:2815-20.

64. Le QT, Kim HE, Schneider CJ, Murakozy G, Skladowski K, Reinisch S, et al. Palifermin reduces severe mucositis in definitive chemoradiotherapy of locally advanced head and neck cancer: a randomized, placebo-controlled study. J Clin Oncol. 2011;29:2808-14.

65. Koukourakis Ml. Amifostine in clinical oncology: current use and future applications. Anticancer Drugs. 2002;13:181-209.

66. Mell LK, Movsas B. Pharmacologic normal tissue protection in clinical radiation oncology: focus on amifostine. Expert Opin Drug Metab Toxicol. 2008:4:1341-50

67. Blijlevens NM, Donnelly JP, Naber AH, Schattenberg AV, DePauw BE. A randomised, double-blinded, placebo-controlled, pilot study of parenteral glutamine for allogeneic stem cell transplant patients. Support Care Cancer. 2005;13:790-6.

68. Cerchietti LC, Navigante AH, Lutteral MA, Castro MA, Kirchuk R, Bonomi M, et al. Double-blinded, placebo-controlled trial on intravenous L-alanyl-Lglutamine in the incidence of oral mucositis following chemoradiotherapy in patients with head-and-neck cancer. Int J Radiat Oncol Biol Phys. 2006;65: 1330-7

69. Peterson DE. New strategies for management of oral mucositis in cancer patients. J Support Oncol. 2006;4:9-13.

70. Vidal-Casariego A, Calleja-Fernandez A, Ballesteros-Pomar MD, CanoRodriguez I. Efficacy of glutamine in the prevention of oral mucositis and acute radiation-induced esophagitis: a retrospective study. Nutr Cancer. 2013:65:424-9.

71. Ward E, Smith M, Henderson M, Reid U, Lewis I, Kinsey S, et al. The effect of high-dose enteral glutamine on the incidence and severity of mucositis in paediatric oncology patients. Eur J Clin Nutr. 2009;63:134-40.
72. Arbabi-kalati F, Deghatipour M, Ansari Moghadam A. Evaluation of the efficacy of zinc sulfate in the prevention of chemotherapy-induced mucositis: a double-blind randomized clinical trial. Arch Iran Med. 2012; 15:413-7.

73. Eilers J, Harris D, Henry K, Johnson LA. Evidence-based interventions for cancer treatment-related mucositis: putting evidence into practice. Clin J Oncol Nurs. 2014;18 Suppl:80-96.

74. Ertekin MV, Koc M, Karslioglu I, Sezen O. Zinc sulfate in the prevention of radiation-induced oropharyngeal mucositis: a prospective, placebocontrolled, randomized study. Int J Radiat Oncol Biol Phys. 2004;58:167-74.

75. Lin LC, Que J, Lin LK, Lin FC. Zinc supplementation to improve mucositis and dermatitis in patients after radiotherapy for head-and-neck cancers: a doubleblind, randomized study. Int J Radiat Oncol Biol Phys. 2006;65:745-50.

76. Rostan EF, DeBuys HV, Madey DL, Pinnell SR. Evidence supporting zinc as an important antioxidant for skin. Int J Dermatol. 2002:41:606-11.

77. Sangthawan D, Phungrassami T, Sinkitjarurnchai W. A randomized doubleblind, placebo-controlled trial of zinc sulfate supplementation for alleviation of radiation-induced oral mucositis and pharyngitis in head and neck cancer patients. J Med Assoc Thai. 2013;96:69-76.

78. Clarkson JE, Worthington HV, Furness S, McCabe M, Khalid T, Meyer S, Interventions for treating oral mucositis for patients with cancer receiving treatment. Cochrane Database Syst Rev 2010:CD001973.

79. Khurana H, Pandey RK, Saksena AK, Kumar A. An evaluation of Vitamin E and Pycnogenol in children suffering from oral mucositis during cancer chemotherapy. Oral Dis. 2013;19:456-64.

80. Sung L, Tomlinson GA, Greenberg ML, Koren G, Judd P, Ota S, et al. Serial controlled $\mathrm{N}$-of-1 trials of topical vitamin $\mathrm{E}$ as prophylaxis for chemotherapy-induced oral mucositis in paediatric patients. Eur J Cancer. 2007;43:1269-75.

81. Cinausero M, Aprile G, Ermacora P, Basile D, Vitale MG, Fanotto V, et al. New Frontiers in the Pathobiology and Treatment of Cancer Regimen-Related Mucosal Injury. Front Pharmacol. 2017:8:354

82. Moslehi A, Taghizadeh-Ghehi M, Gholami K, Hadjibabaie M, JahangardRafsanjani Z, Sarayani A, et al. N-acetyl cysteine for prevention of oral mucositis in hematopoietic SCT: a double-blind, randomized, placebocontrolled trial. Bone Marrow Transplant. 2014;49:818-23.

83. Blakaj A, Bonomi M, Gamez ME, Blakaj DM. Oral mucositis in head and neck cancer: Evidence-based management and review of clinical trial data. Oral Oncol. 2019;95:29-34.

84. Rao S, Dinkar C, Vaishnav LK, Rao P, Rai MP, Fayad R, et al. The Indian Spice Turmeric Delays and Mitigates Radiation-Induced Oral Mucositis in Patients Undergoing Treatment for Head and Neck Cancer: An Investigational Study. Integr Cancer Ther. 2014;13:201-10.

85. Giralt J, Tao Y, Kortmann RD, Zasadny X, Contreras-Martinez J, Ceruse P, et al. Randomized Phase 2 Trial of a Novel Clonidine Mucoadhesive Buccal Tablet for the Amelioration of Oral Mucositis in Patients Treated With Concomitant Chemoradiation Therapy for Head and Neck Cancer. Int J Radiat Oncol Biol Phys. 2020;106:320-8.

86. Han G, Bian L, Li F, Cotrim A, Wang D, Lu J, et al. Preventive and therapeutic effects of Smad7 on radiation-induced oral mucositis. Nat Med. 2013;19:421-8.

87. Epstein JB, Silverman S Jr, Paggiarino DA, Crockett S, Schubert MM, Senzer $\mathrm{NN}$, et al. Benzydamine $\mathrm{HCl}$ for prophylaxis of radiation-induced oral mucositis: results from a multicenter, randomized, double-blind, placebocontrolled clinical trial. Cancer. 2001;92:875-85.

88. Kazemian A, Kamian S, Aghili M, Hashemi FA, Haddad P. Benzydamine for prophylaxis of radiation-induced oral mucositis in head and neck cancers: a double-blind placebo-controlled randomized clinical trial. Eur J Cancer Care (Engl). 2009;18:174-8.

89. Gruber S, Schmidt M, Bozsaky E, Wolfram K, Haagen J, Habelt B, et al. Modulation of radiation-induced oral mucositis by pentoxifylline: preclinical studies. Strahlenther Onkol. 2015;191:242-7.

90. Sayed R, El Wakeel L, Saad AS, Kelany M, El-Hamamsy M. Pentoxifylline and vitamin $\mathrm{E}$ reduce the severity of radiotherapy-induced oral mucositis and dysphagia in head and neck cancer patients: a randomized, controlled study. Med Oncol. 2019;37:8.

91. Kudrimoti M, Curtis A, Azawi S, Worden F, Katz S, Adkins D, et al. Dusquetide: A novel innate defense regulator demonstrating a significant and consistent reduction in the duration of oral mucositis in preclinical data and a randomized, placebo-controlled phase 2a clinical study. J Biotechnol. 2016:239:115-25. 
92. Biswal BM, Zakaria A, Ahmad NM. Topical application of honey in the management of radiation mucositis: a preliminary study. Support Care Cancer. 2003;11:242-8.

93. Khanal B, Baliga M, Uppal N. Effect of topical honey on limitation of radiation-induced oral mucositis: an intervention study. Int J Oral Maxillofac Surg. 2010;39:1181-5.

94. Motallebnejad M, Akram S, Moghadamnia A, Moulana Z, Omidi S. The effect of topical application of pure honey on radiation-induced mucositis: a randomized clinical trial. J Contemp Dent Pract. 2008;9:40-7.

95. Rashad UM, Al-Gezawy SM, El-Gezawy E, Azzaz AN. Honey as topical prophylaxis against radiochemotherapy-induced mucositis in head and neck cancer. J Laryngol Otol. 2009;123:223-8.

96. Maddocks-Jennings W, Wilkinson JM, Cavanagh HM, Shillington D. Evaluating the effects of the essential oils Leptospermum scoparium (manuka) and Kunzea ericoides (kanuka) on radiotherapy induced mucositis: a randomized, placebo controlled feasibility study. Eur J Oncol Nurs. 2009; 13:87-93.

97. You WC, Hsieh CC, Huang JT. Effect of extracts from indigowood root (Isatis indigotica Fort.) on immune responses in radiation-induced mucositis. J Altern Complement Med. 2009;15:771-8.

98. Loo WT, Jin LJ, Chow LW, Cheung MN, Wang M. Rhodiola algida improves chemotherapy-induced oral mucositis in breast cancer patients. Expert Opin Investig Drugs. 2010;19(Suppl 1):91-100.

99. Carl W, Emrich LS. Management of oral mucositis during local radiation and systemic chemotherapy: a study of 98 patients. J Prosthet Dent. 1991;66: 361-9.

100. Fidler P, Loprinzi CL, O'Fallon JR, Leitch JM, Lee JK, Hayes DL, et al. Prospective evaluation of a chamomile mouthwash for prevention of 5-FUinduced oral mucositis. Cancer. 1996;77:522-5.

101. Su CK, Mehta V, Ravikumar L, Shah R, Pinto H, Halpern J, et al. Phase II double-blind randomized study comparing oral aloe vera versus placebo to prevent radiation-related mucositis in patients with head-and-neck neoplasms. Int J Radiat Oncol Biol Phys. 2004;60:171-7.

102. Naidu MU, Ramana GV, Ratnam SV, Sudhavani T, Naidu KJ, Roy P, et al. A randomised, double-blind, parallel, placebo-controlled study to evaluate the efficacy of MF 5232 (Mucotrol), a concentrated oral gel wafer, in the treatment of oral mucositis. Drugs R D. 2005;6:291-8.

103. Oberbaum M, Yaniv I, Ben-Gal Y, Stein J, Ben-Zvi N, Freedman LS, et al. A randomized, controlled clinical trial of the homeopathic medication TRAUMEEL $S$ in the treatment of chemotherapy-induced stomatitis in children undergoing stem cell transplantation. Cancer. 2001;92:684-90.

104. Chaveli-Lopez B, Bagan-Sebastian JV. Treatment of oral mucositis due to chemotherapy. J Clin Exp Dent. 2016;8:e201-9.

105. Peterson DE, Boers-Doets CB, Bensadoun RJ, Herrstedt J. Management of oral and gastrointestinal mucosal injury: ESMO Clinical Practice Guidelines for diagnosis, treatment, and follow-up. Ann Oncol. 2015;26(Suppl 5):v139-151.

106. Mego M, Chovanec J, Vochyanova-Andrezalova I, Konkolovsky P, Mikulova $M$, Reckova $M$, et al. Prevention of irinotecan induced diarrhea by probiotics: A randomized double blind, placebo controlled pilot study. Complement Ther Med. 2015;23:356-62.

107. Prisciandaro LD, Geier MS, Butler RN, Cummins AG, Howarth GS. Probiotic factors partially improve parameters of 5-fluorouracil-induced intestinal mucositis in rats. Cancer Biol Ther. 2011;11:671-7.

108. Elad S, Cheng KKF, Lalla RV, Yarom N, Hong C, Logan RM, et al. MASCC/ ISOO clinical practice guidelines for the management of mucositis secondary to cancer therapy. Cancer. 2020;126:4423-31.

109. Ferraiuolo M, Pulito C, Finch-Edmondson M, Korita E, Maidecchi A, Donzelli $S$, et al. Agave negatively regulates YAP and TAZ transcriptionally and posttranslationally in osteosarcoma cell lines. Cancer Lett. 2018;433:18-32.

110. Godwin P, Baird AM, Heavey S, Barr MP, O'Byrne K, Gately K. Targeting nuclear factor-kappa B to overcome resistance to chemotherapy. Front Oncol. 2013:3:120.

111. Pulito C, Korita E, Sacconi A, Valerio M, Casadei L, Lo Sardo F, et al. Dropwort-induced metabolic reprogramming restrains YAP/TAZ/TEAD oncogenic axis in mesothelioma. J Exp Clin Cancer Res. 2019:38:349.

112. Pulito C, Mori F, Sacconi A, Casadei L, Ferraiuolo M, Valerio MC, et al. Cynara scolymus affects malignant pleural mesothelioma by promoting apoptosis and restraining invasion. Oncotarget. 2015;6:18134-50.

113. Yarom N, Ariyawardana A, Hovan A, Barasch A, Jarvis V, Jensen SB, et al. Systematic review of natural agents for the management of oral mucositis in cancer patients. Support Care Cancer. 2013;21:3209-21.
114. Lopes NN, Plapler H, Chavantes MC, Lalla RV, Yoshimura EM, Alves MT. Cyclooxygenase-2 and vascular endothelial growth factor expression in 5fluorouracil-induced oral mucositis in hamsters: evaluation of two lowintensity laser protocols. Support Care Cancer. 2009;17:1409-15.

115. Lopes NN, Plapler H, Lalla RV, Chavantes MC, Yoshimura EM, da Silva MA, et al. Effects of low-level laser therapy on collagen expression and neutrophil infiltrate in 5-fluorouracil-induced oral mucositis in hamsters. Lasers Surg Med. 2010;42:546-52.

116. Basso FG, Oliveira CF, Kurachi C, Hebling J, Costa CA. Biostimulatory effect of low-level laser therapy on keratinocytes in vitro. Lasers Med Sci. 2013;28: 367-74

117. Kujawa J, Zavodnik L, Zavodnik I, Buko V, Lapshyna A, Bryszewska M. Effect of low-intensity $(3.75-25 \mathrm{~J} / \mathrm{cm} 2)$ near-infrared $(810 \mathrm{~nm})$ laser radiation on red blood cell ATPase activities and membrane structure. J Clin Laser Med Surg. 2004;22:111-7.

118. Sonis ST, Hashemi S, Epstein JB, Nair RG, Raber-Durlacher JE. Could the biological robustness of low level laser therapy (Photobiomodulation) impact its use in the management of mucositis in head and neck cancer patients. Oral Oncol. 2016;54:7-14.

119. Lalla RV, Bowen J, Barasch A, Elting L, Epstein J, Keefe DM, et al. MASCC/ ISOO clinical practice guidelines for the management of mucositis secondary to cancer therapy. Cancer. 2014;120:1453-61.

120. Cerchietti LC, Navigante AH, Korte MW, Cohen AM, Quiroga PN, Villaamil EC, et al. Potential utility of the peripheral analgesic properties of morphine in stomatitis-related pain: a pilot study. Pain. 2003;105:265-73.

121. Allison RR, Ambrad AA, Arshoun Y, Carmel RJ, Ciuba DF, Feldman E, et al. Multi-institutional, randomized, double-blind, placebo-controlled trial to assess the efficacy of a mucoadhesive hydrogel (MuGard) in mitigating oral mucositis symptoms in patients being treated with chemoradiation therapy for cancers of the head and neck. Cancer. 2014;120:1433-40

122. Elting LS, Cooksley CD, Chambers MS, Garden AS. Risk, outcomes, and costs of radiation-induced oral mucositis among patients with head-and-neck malignancies. Int J Radiat Oncol Biol Phys. 2007;68:1110-20.

123. Citrin DE, Hitchcock YJ, Chung EJ, Frandsen J, Urick ME, Shield W, et al. Determination of cytokine protein levels in oral secretions in patients undergoing radiotherapy for head and neck malignancies. Radiat Oncol. 2012;7:64.

124. Xanthinaki A, Nicolatou-Galitis O, Athanassiadou P, Gonidi M, Kouloulias V, Sotiropoulou-Lontou A, et al. Apoptotic and inflammation markers in oral mucositis in head and neck cancer patients receiving radiotherapy: preliminary report. Support Care Cancer. 2008;16:1025-33.

125. Meirovitz A, Kuten M, Billan S, Abdah-Bortnyak R, Sharon A, Peretz T, et al. Cytokines levels, severity of acute mucositis and the need of PEG tube installation during chemo-radiation for head and neck cancer-a prospective pilot study. Radiat Oncol. 2010;5:16.

126. Seyyednejad F, Rezaee A, Haghi S, Goldust M. Survey of pre-inflammation cytokines levels in radiotherapy-induced-mucositis. Pak J Biol Sci. 2012;15: 1098-101.

127. Chen HW, Chang YC, Lai YL, Chen YJ, Huang MJ, Leu YS, et al. Change of plasma transforming growth factor-beta1 levels in nasopharyngeal carcinoma patients treated with concurrent chemo-radiotherapy. Jpn J Clin Oncol. 2005;35:427-32.

128. Chen HW, Yang SF, Chang YC, Wang TY, Chen YJ, Hwang JJ. Epstein-Barr virus infection and plasma transforming growth factor-beta1 levels in head and neck cancers. Acta Otolaryngol. 2008;128:1145-51.

129. Epstein JB, Emerton S, Guglietta A, Le N. Assessment of epidermal growth factor in oral secretions of patients receiving radiation therapy for cancer. Oral Oncol. 1997;33:359-63.

130. Epstein JB, Gorsky M, Guglietta A, Le N, Sonis ST. The correlation between epidermal growth factor levels in saliva and the severity of oral mucositis during oropharyngeal radiation therapy. Cancer. 2000;89:2258-65.

131. Dumbrigue HB, Sandow PL, Nguyen KH, Humphreys-Beher MG. Salivary epidermal growth factor levels decrease in patients receiving radiation therapy to the head and neck. Oral Surg Oral Med Oral Pathol Oral Radiol Endod. 2000;89:710-6.

132. Ki Y, Kim W, Nam J, Kim D, Park D. C-reactive protein levels and radiationinduced mucositis in patients with head-and-neck cancer. Int J Radiat Oncol Biol Phys. 2009;75:393-8.

133. Ehrsson YT, Hellstrom PM, Brismar K, Sharp L, Langius-Eklof A, Laurell G. Explorative study on the predictive value of systematic inflammatory and 
metabolic markers on weight loss in head and neck cancer patients undergoing radiotherapy. Support Care Cancer. 2010;18:1385-91.

134. Mohammed FF, Poon I, Zhang L, Elliott L, Hodson ID, Sagar SM, et al. Acutephase response reactants as objective biomarkers of radiation-induced mucositis in head and neck cancer. Head Neck. 2012;34:985-93.

135. Chethana, Rao PS, Madathil LP, Rao S, Shetty P, Patidar M. Quantitative Analysis of Acute Phase Proteins in Post Chemo-Radiation Mucositis. J Clin Diagn Res. 2015;9:ZC28-31.

136. Bhattathiri VN, Sreelekha TT, Sebastian P, Remani P, Chandini R, Vijayakumar $T$, et al. Influence of plasma GSH level on acute radiation mucositis of the oral cavity. Int J Radiat Oncol Biol Phys. 1994;29:383-6.

137. Wardman P, Folkes LK, Bentzen SM, Stratford MR, Hoskin PJ, Phillips H, et al. Influence of plasma glutathione levels on radiation mucositis. Int J Radiat Oncol Biol Phys. 2001;51:460-4.

138. Li P, Du CR, Xu WC, Shi ZL, Zhang Q, Li ZB, et al. Correlation of dynamic changes in gamma-H2AX expression in peripheral blood lymphocytes from head and neck cancer patients with radiation-induced oral mucositis. Radiat Oncol. 2013;8:155.

139. Fleckenstein J, Kuhne M, Seegmuller K, Derschang S, Melchior P, Graber S, et al. The impact of individual in vivo repair of DNA double-strand breaks on oral mucositis in adjuvant radiotherapy of head-and-neck cancer. Int J Radiat Oncol Biol Phys. 2011;81:1465-72.

140. Gonzalez-Arriagada WA, Ramos LM, Silva AA, Vargas PA, Coletta RD, Bingle $L$, et al. Salivary BPIFA1 (SPLUNC1) and BPIFA2 (SPLUNC2 A) are modified by head and neck cancer radiotherapy. Oral Surg Oral Med Oral Pathol Oral Radiol. 2015;119:48-58.

141. Handschel J, Prott FJ, Sunderkotter C, Metze D, Meyer U, Joos U. Irradiation induces increase of adhesion molecules and accumulation of beta2integrin-expressing cells in humans. Int J Radiat Oncol Biol Phys. 1999;45: 475-81.

142. Normando AGC, Rocha CL, de Toledo IP, de Souza Figueiredo PT, Dos Reis PED, De Luca Canto G, et al. Biomarkers in the assessment of oral mucositis in head and neck cancer patients: a systematic review and meta-analysis. Support Care Cancer. 2017;25:2969-88.

143. Pulito C, Terrenato I, Di Benedetto A, Korita E, Goeman F, Sacconi A, et al, $C d \times 2$ polymorphism affects the activities of vitamin $D$ receptor in human breast cancer cell lines and human breast carcinomas. PLoS One. 2015;10: e0124894.

144. Pratesi N, Mangoni M, Mancini I, Paiar F, Simi L, Livi L, et al. Association between single nucleotide polymorphisms in the XRCC1 and RAD51 genes and clinical radiosensitivity in head and neck cancer. Radiother Oncol. 2011; 99:356-61.

145. Venkatesh GH, Manjunath VB, Mumbrekar KD, Negi H, Fernandes DJ, Sharan $\mathrm{K}$, et al. Polymorphisms in radio-responsive genes and its association with acute toxicity among head and neck cancer patients. PLoS One. 2014;9: e89079.

146. Werbrouck J, De Ruyck K, Duprez F, Veldeman L, Claes K, Van Eijkeren M, et al. Acute normal tissue reactions in head-and-neck cancer patients treated with IMRT: influence of dose and association with genetic polymorphisms in DNA DSB repair genes. Int J Radiat Oncol Biol Phys. 2009; 73:1187-95.

147. Gutierrez-Camino A, Oosterom N, den Hoed MAH, Lopez-Lopez E, MartinGuerrero I, Pluijm SMF, et al. The miR-1206 microRNA variant is associated with methotrexate-induced oral mucositis in pediatric acute lymphoblastic leukemia. Pharmacogenet Genomics. 2017;27:303-6.

148. Laheij A, Raber-Durlacher JE, Koppelmans RGA, Huysmans M, Potting C, van Leeuwen SJM, et al. Microbial changes in relation to oral mucositis in autologous hematopoietic stem cell transplantation recipients. Sci Rep. 2019;9:16929.

149. Gawronski KAB, Kim J. Single cell transcriptomics of noncoding RNAs and their cell-specificity. Wiley Interdiscip Rev RNA. 2017;8. https://doi.org/10. 1002/wrna.1433

150. Grillone K, Riillo C, Scionti F, Rocca R, Tradigo G, Guzzi PH, et al. Non-coding RNAs in cancer: platforms and strategies for investigating the genomic "dark matter". J Exp Clin Cancer Res. 2020;39:117.

151. Zhang Y, Liang W, Zhang P, Chen J, Qian H, Zhang X, et al. Circular RNAs: emerging cancer biomarkers and targets. J Exp Clin Cancer Res. 2017;36:152.

\section{Publisher's Note}

Springer Nature remains neutral with regard to jurisdictional claims in published maps and institutional affiliations.

\section{Ready to submit your research? Choose BMC and benefit from}

- fast, convenient online submission

- thorough peer review by experienced researchers in your field

- rapid publication on acceptance

- support for research data, including large and complex data types

- gold Open Access which fosters wider collaboration and increased citations

- maximum visibility for your research: over $100 \mathrm{M}$ website views per year

At BMC, research is always in progress.

Learn more biomedcentral.com/submissions 